Silva, J.F.; Brandão, J.O.S. Turismo, gestão participativa e sustentabilidade: caso da Vila do Aventureiro (RJ). Revista Brasileira de Ecoturismo, São Paulo, v.6, n.2, mai/jul-2013, pp.586601.

\title{
Turismo, gestão participativa e sustentabilidade: caso da Vila do Aventureiro (RJ)
}

\author{
Tourism, participatory management and sustainability: the case of \\ Vila do Aventureiro (RJ, Brazil)
}

\author{
Juliana Fernandes da Silva, Juzânia Oliveira da Silva Brandão
}

\section{RESUMO}

Este artigo aborda a gestão participativa para o desenvolvimento sustentável de comunidades tradicionais, tendo em vista o Turismo para a autogestão e a preservação das tradições. A comunidade a ser analisada é a Vila do Aventureiro, na llha Grande, Angra dos Reis (RJ), que se baseia historicamente nas atividades de subsistência e está situada na Reserva Biológica da Praia do Sul. O presente estudo fundamenta-se em pesquisas em campo feitas entre 2011 e 2012, para uma dissertação de mestrado em Turismo, em curso. Através de pesquisa bibliográfica, buscamos dar ao trabalho um embasamento teórico, o que foi comparado com a realidade da comunidade, por meio dos dados obtidos em entrevistas, observação direta e participação nas práticas cotidianas. O desenvolvimento sustentável, um ideal de desenvolvimento das atividades cotidianas, do realizar do modo de vida, sem agredir seus protagonistas e o meio ambiente está intrinsecamente ligado às ações comunitárias, partindo da consciência individual à coletiva. Comunidades tradicionais têm raízes fortes com sua terra. Contudo, dentro de algumas Unidades de Conservação, são vistas como destruidoras das áreas naturais por parte dos órgãos ambientais, que fazem o caminho reverso à sustentabilidade quando separam a relação homem-natureza, tornando-as insustentáveis. Mas a comunidade pode ganhar força contra uma insustentabilidade imposta, através da gestão participativa de suas atividades e, particularmente, do Turismo, com mobilização e participação democrática, embasado na solidariedade e no sentimento de pertencimento, reavivando sua memória e identidade continuamente. No Aventureiro, apesar da solidariedade tradicional, notamos um certo desgaste nas relações de confiança, ocasionado pelos marcos históricos de interdição cultural.

PALAVRAS-CHAVE: Turismo Comunitário; Gestão Participativa; Sustentabilidade; Unidades de Conservação. 


\begin{abstract}
This article approaches participatory management for sustainable development of traditional communities, in view of Tourism for automanagement and preservation of traditions. The community that will be analysed is Aventureiro Village, in Ilha Grande, Angra dos Reis (RJ), which is historically based on subsistence activities and are located on Praia do Sul Biological Reserve. The present study is based upon researches between 2011 and 2012, for a dissertation of a Master of Tourism, in course. Through bibliographic research, we aim to form the theoretical base, what was compared to community's reality by data collected by interviews, direct observation and participation in daily group practices. Sustainable development, an idealisation of development for daily tasks, for way of life, not degrading its protagonists and environment, is intrinsically connected to community actions, from individual to collective conscience. Traditional communities have got strong connection with their land. However, inside of some protected areas, they are perceived as natural areas destroyers by environmental governmental agencies, which go on reverse way to sustainability, when detaching Human-Nature relation, making them become unsustainable. But community may become stronger against an enforced sustainability, pursuit of participatory management of its activities and, particularlly, of Tourism, with mobilization and democratic participation, based on solidarity and belonging feeling, reviving its memory and identity constantly. In Aventureiro, in spite of their traditional solidarity, we notice an erosion in trust relations, created by historical signs of cultural interdiction.
\end{abstract}

KEYWORDS: Community-based Tourism; Participatory Management; Sustainability; Protected Areas.

\title{
Introdução
}

O Turismo vem, por muito tempo, sendo estudado de uma forma analítica, em que o anfitrião e o turista não passam de números para satisfazer o setor econômico. Porém, Morin (2011) propõe uma forma mais autêntica e global de análise nos campos que envolvem relações sociais, visto por ele com a necessidade de entender a complexidade dessas relações, tanto através de cada parte envolvida como o todo que ali está presente.

Este artigo apresenta uma abordagem qualitativa, porque nos importa iluminar os processos sociais pelos quais a Vila do Aventureiro passa, tendo o Turismo Comunitário e a gestão participativa como foco.

O levantamento bibliográfico e documental foi feito a fim de se construir um embasamento teórico para este ensaio, no decorrer da construção do trabalho, com base em publicações, tais como livros, dissertações, teses e artigos científicos, a respeito dos temas traçados. Algumas pesquisas em campo ocorreram entre 2011 e 2012 mediante observação e entrevistas. A observação das práticas cotidianas da comunidade contou com participação nas atividades para maior integração com os moradores a 
fim de garantir resultados mais reais, e para levantamento mais profundo de seu modo de vida, e da relação entre comunidade e turistas. Entrevistas foram feitas em forma de conversas informais e semiestruturadas, com os moradores e representantes do INEA presentes na comunidade, com posterior tomada de notas de campo, relatando detaIhes das observações e entrevistas feitas.

Propomos aqui retirar as vendas para as formas de planejamento e gestão público-privada, em que quem sai perdendo mais é a comunidade, sendo muitas vezes marginalizada dos projetos e ações, nos quais o imediatismo por retornos financeiros são prioridade, utilizando-se dos recursos ambientais, culturais da comunidade como simples produtos a serem comercializados como em uma "prateleira de supermercado", e quem é o detentor do poderio econômico pode se apropriar de forma indiscriminada.

Vemos a gestão participativa, através das práticas cotidianas da comunidade e, particularmente, do Turismo Comunitário, como um caminho o qual pode ser percorrido para se chegar ao nível ora ideal da sustentabilidade, principalmente em pequenas comunidades e comunidades tradicionais dentro de Unidades de Conservação ou em seu entorno, geridas por órgãos ambientais, às vezes, socialmente excludentes. E é por perspectiva que nos utilizamos da realidade vivenciada na Vila do Aventureiro para dissertar sobre a emergência de uma mudança no planejamento do Turismo.

O conceito de sustentabilidade sugere práticas menos danosas e uma real mobilização pelo bem-estar das populações e pela preservação da natureza. Sabemos que isso requer novas atitudes, direcionadas para o desenvolvimento local, para a continuidade dos modos de vida, sem agredir o ambiente de (sobre)vivência. Sim, é uma questão de autopreservação, em que se busca prolongar as condições que mantêm vivos os homens e os demais seres biológicos, com princípios ambientais, socioculturais, econômicos e político-institucionais.

O desenvolvimento de comunidades sustentáveis parte de uma consciência individual, visto que os indivíduos são parte do todo - a comunidade, para uma consciência coletiva. Em uma comunidade sustentável, os saberes são transmitidos e herdados historicamente, com respeito ao ambiente que a envolve.

As comunidades tradicionais dependem intrinsecamente da natureza e sobre ela reservam profundo conhecimento empírico. O afastamento de seu ambiente de vida causa mudanças estruturais no modo de vida e adaptação a uma nova realidade de interdição parcial ou total de suas tradições. Assim, as Unidades de Conservação e os órgãos ambientais impõem uma insustentabilidade arbitrariamente, externa à realidade da população.

O Turismo Comunitário surge com a peculiaridade de ser conduzido por pessoas "do lugar", prezando pelo ideal de sustentabilidade através das ações comunitárias, garantindo o poder endógeno. Podemos relacionar sua importância ao fato de haver um autorreconhecimento e valorização de sua identidade. Então, o comprometimento da comunidade é fator fundamental para a ocorrência harmônica do Turismo. Com isso, beneficia, além dos moradores, os turistas, que vivenciam de fato a cultura do lugar. 


\section{Vila do Aventureiro em linhas gerais}

Antes que sejam feitas as reflexões teóricas, é preciso apresentar as características gerais da comunidade em questão. A Vila do Aventureiro situa-se na llha Grande, que está localizada nos limites territoriais do município de Angra dos Reis, na região Sul do Estado do Rio de Janeiro. A Ilha é a maior do Estado, com 193km², "a $150 \mathrm{~km}$ do Rio de Janeiro e a $400 \mathrm{~km}$ de São Paulo, dois grandes centros urbanos" (SANTOS, 2006, p.445), em área de Mata Atlântica.

A Vila do Aventureiro (Figura 1) localiza-se nas coordenadas geográficas "23을 10'S, 44ํ 17' W" (BIDEGAIN; FRESCHI, 2009, p.10), a sudoeste na llha Grande, na Praia do Aventureiro, que tem cerca de 800 metros de comprimento, sendo seu acesso

A leste pelo mar e a oeste pela crista da serra, que sobe gradativamente até atingir 464 metros a sudeste, e é limitada pela Ponta do Aventureiro e pelas pedras que a separam da Praia do Demo a nordeste (VILAÇA; MAIA, 2006, p. 66).

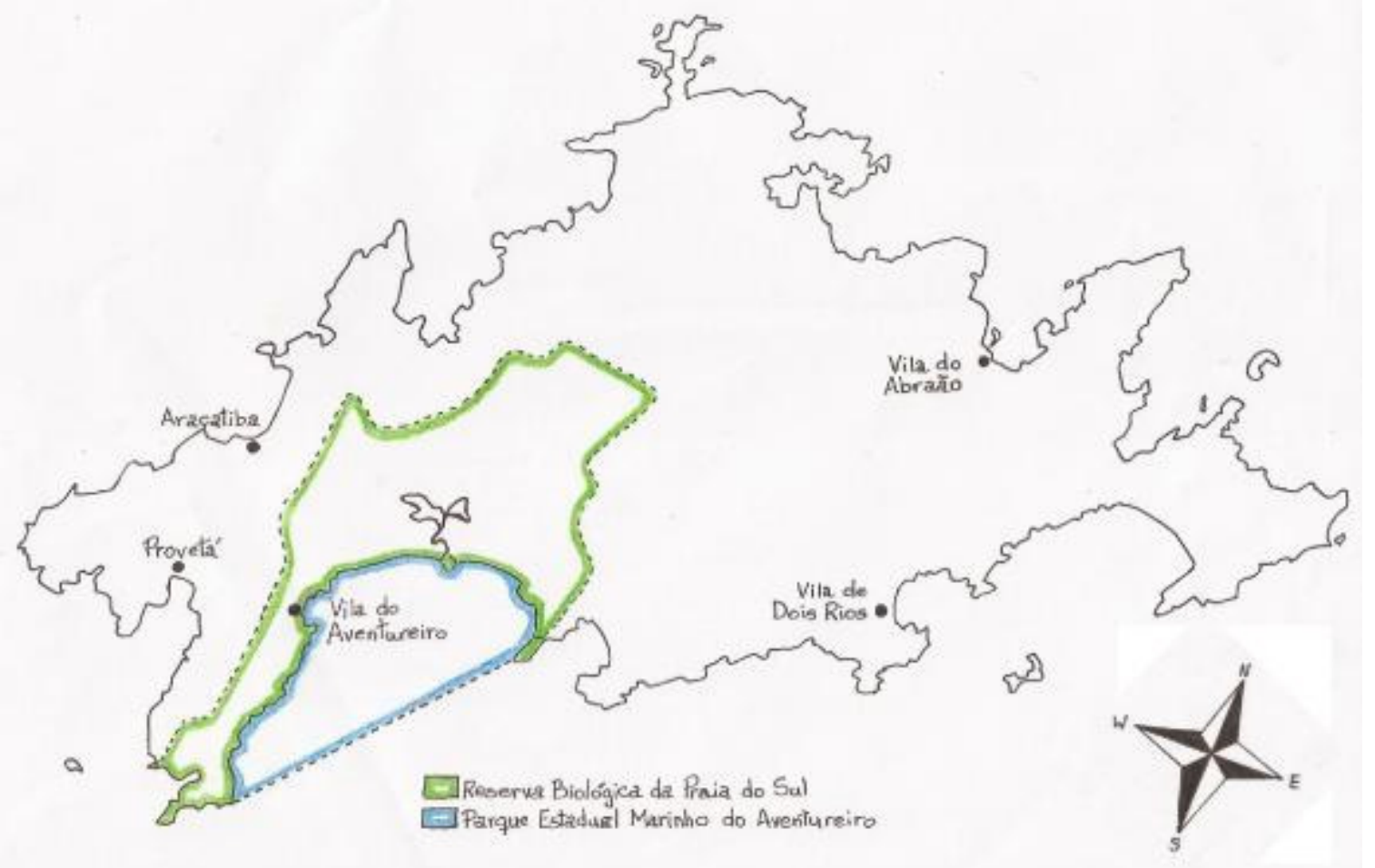

Figura 1: Localização da Vila do Aventureiro, da llha Grande (RJ).

Figure 1: Location Vila do Aventureiro, Ilha Grande (RJ, Brazil)

O nome "Praia do Aventureiro", segundo relatos dos próprios moradores da llha Grande, deve-se ao relativo isolamento da comunidade, por estar circundada por montanha e mar, e por estarem à mercê do clima, no inverno, quando o mar fica 
"grosso" e há maior ocorrência do vento Sudoeste, o "mais respeitado" pela população de lá. Por esse motivo, segundo alguns moradores, "quem consegue chegar lá, é muito aventureiro".

Seu modo de vida é baseado em atividades ligadas à terra, como o cultivo da roça, a produção de farinha-da-roça, a produção de vinagre de banana; o artesanato, com a produção de cestarias, tapiti, canoas de guapuruvu; a construção da casa de estuque; a pesca artesanal. Essas práticas são feitas por meio de mutirão, embora em menor escala que antes, devido às restrições impostas pelo Fundação Estadual de Engenharia do Meio Ambiente (FEEMA), órgão ambiental da época. Mais recentemente, a partir da década de 1990, por causa da desativação do Centro Correcional de Dois Rios, receber turistas também passou a fazer parte dos costumes da comunidade.

\section{Comunidades sustentáveis}

O conceito de sustentabilidade tem sido proclamado pelas organizações do setor privado como uma ferramenta de marketing, de modo que demonstre sua "responsabilidade socioambiental" indiscriminadamente. Segundo Capra (1997), esse conceito tem a ver com "reconectar-se com a teia da vida", que, para o autor, significa "construir, nutrir e educar comunidades sustentáveis", o que sugere um convívio mais próximo com a natureza e práticas menos danosas, uma mobilização real por ações integradas a fim de se alcançar o status ora ideal de sustentabilidade. Na maioria das vezes, é necessário (re)construir o modo de vida das comunidades de maneira "mais sustentável" e, para isso, a educação e a formação de consciência sobre sua responsabilidade social, ambiental e econômica toma lugar central nessa discussão.

A expressão Desenvolvimento Sustentável é apresentada no Relatório de Brundtland, "Nosso Futuro Comum", elaborado em 1987, com o seguinte contexto:

\footnotetext{
Desenvolvimento Sustentável é um processo de transformação no qual a exploração de recursos, a direção dos investimentos, a orientação do desenvolvimento tecnológico e a mudança institucional se harmonizam e reforçam o potencial presente e futuro, a fim de atender às necessidades e aspirações humanas (CMMAD, 1991, s/p).
}

Buarque (2001, p.36) argumenta que o conceito do desenvolvimento sustentável é "uma construção teórica para organizar uma nova postura da sociedade diante dos desafios do presente o do futuro e consistente com o novo paradigma de desenvolvimento", que requer uma atitude quanto ao que se quer para o desenvolvimento local, e, apesar de haver um planejamento para o tempo presente e para as futuras gerações, não é uma ideia meramente ideológica. Basta olhar ao redor para perceber a necessidade de um novo agir em sociedade, que viabiliza a mudança no presente para possibilitar um futuro melhor. 
O desenvolvimento sustentável é um ideal de desenvolvimento de atividades cotidianas que baseiam sua existência no realizar dos modos de vida e produção de forma que, individual e coletivamente, haja qualidade de vida e bem-estar para a população, sem que se agrida o ambiente de (sobre)vivência.

Não é somente o fato de preservar os ambientes, as culturas, a sociedade; essa é uma questão de autopreservação, visto que, preservando o espaço e o modo de vida, está buscando o prolongamento das condições que mantêm vivos os homens e todos os outros elementos biológicos, culturais, sociais relacionados a ele. Ainda, para Buarque (2001), o desenvolvimento sustentável baseia-se em dois tipos de solidariedade, sendo que "a solidariedade intrageração é uma condição indispensável para a solidariedade intergerações", no sentido de que, para se pensar em um ambiente para seus futuros moradores e visitantes, é imprescindível agir no tempo presente para a melhoria das condições de vida.

Por mais que pareça ideal, o desenvolvimento sustentável tenta melhorar a qualidade de vida da comunidade local. E que esta melhoria reflita no interesse do visitante para participar da construção de uma sociedade mais igualitária. E que o turista carregue consigo esse ideal e tenha ações compatíveis com ele.

Vale lembrar que a sustentabilidade aponta para uma nova forma de governança que seja "sempre dissociada dos impulsos do imediatismo, dos resultados de eficiência em curto prazo, em geral preconizados nos processos de planejamento que acompanham interesses econômicos e políticos individuais ou de pequenos grupos" (PENA; BRASILEIRO; SANTOS, 2012), já que não é interessante aumentar ainda mais as desigualdades causadas pelo desenvolvimento desenfreado.

Atingir o nível de sustentabilidade está ligado às ações comunitárias. Capra (1996) afirma que, para isso, as comunidades humanas teriam que tornar seu pensamento à natureza, pensar como comunidades ecológicas que são, já que a única diferença entre essas e as comunidades humanas é que "nos ecossistemas não existe autopercepção, nem linguagem, nem consciência e nem cultura". Logo, a diferença entre elas está em perceber sua vida, pensar sobre ela e agir mediante suas vontades e sentimentos. É o que Sahlins (2003) chamou de "intenção cultural".

O cerne da questão de comunidades insustentáveis, como se pode perceber no artigo "The Tragedy of the Commons", de Garrett Hardin (1968), está nos "atos sem remorso" (tradução nossa), aqueles em que a ação cognoscente não está voltada à coletividade, mas somente aos ganhos individuais. Buarque (2001) indica que o desenvolvimento sustentável prenuncia "uma sociedade com equidade social e conservação ambiental", enquanto Pena, Brasileiro e Souza (2012) citam que ele "deve ser construído para, por meio de e com a sociedade local', o que significa dizer que o desenvolvimento sustentável não reside em ações aleatórias e sem pretensões, mas com objetivos estabelecidos na sociedade atual, de acordo com suas perspectivas de mudança social para melhoria de sua qualidade de vida atual e futura.

O desenvolvimento de comunidades sustentáveis parte de uma consciência individual, respaldado pela consciência coletiva, na relação de seus elementos entre si, entre seus elementos e o meio ambiente, entre seus elementos e outros "de fora". 
Entretanto, não se deve esquecer que, por vezes, o impasse sobre a sustentabilidade está na dimensão político-institucional. Por isso, é essencial reunir todos os setores sociais da comunidade, para que, por mais que tenham interesses distintos, possam trabalhar em direção ao bem maior da comunidade.

Essa perspectiva contempla todos os envolvidos não só no Turismo, mas no cotidiano da comunidade, podendo beneficiá-la de forma mais equilibrada, visando de fato à sustentabilidade em todas as esferas e garantindo o desenvolvimento equilibrado. Além disso, Dias (2004, p.31) cita, bem pontual, que "o desenvolvimento sustentável só é atingido com justiça social" alertando quanto ao risco de pensar no Turismo utilitarista e imediatista. É nessa premissa que o Turismo Comunitário encontra sua razão, focando no desenvolvimento comunitário e o envolvimento da comunidade na atividade turística, dando ao turista a oportunidade de vivência da cultura do lugar.

Uma sociedade sustentável é aquela em que os saberes inerentes a sua vida, produção e contato com o ambiente são transmitidos e herdados entre as gerações historicamente, o que também é abordado por Laraia (2001), quando cita que "toda a experiência de um indivíduo é transmitida aos demais, criando assim um interminável processo de acumulação", em que a comunicação, principalmente na transmissão oral de saberes, tem papel fundamental para a sustentabilidade. Assim, com comunicação entre os indivíduos, os comportamentos e saberes identitários não se extinguem.

Apesar de, atualmente, as atividades tradicionais se darem com menor intensidade, ocorre com os "Filhos do Aventureiro", ou "Povo do Aventureiro" como cita Vilaça e Maia (2006), que são transmitidos os saberes e exercidos, "em suas relações de parentesco e compadrio, suas atividades e seus rituais". Seus resultados são tradicionalmente divididos entre seus participantes, como acontece no caso da produção de farinha, em que, quem participa, recebe uma parcela da produção; e da pesca, em que os peixes são divididos entre as famílias cujos membros entraram com a canoa no mar ou puxaram a rede na praia, e na base da troca. Assim também ocorre com os saberes, que não são apenas transmitidos dentro da família, por meio da tradição oral, de pai para filho ou de mãe para filha, mas às demais pessoas pertencentes à comunidade, através do compadrio. Mas o que se percebe é que, com a criação da REBIO e do Parque Marinho, aconteceram algumas interdições no modo de vida dos "Filhos do Aventureiro", sendo que alguns de seus costumes encerraram-se no campo do "fazer", permanecendo apenas no campo do "saber-fazer", o que tende a se extinguir caso continue o ciclo de interdições, já que alguns jovens da vila já nasceram dentro do "tempo da REBIO".

\section{Unidades de Conservação: preservação e limitações para as comunidades}

Com o movimento ambientalista iniciado entre as décadas de 1960 e 1970, surgido pela preocupação com o "progresso" "civilizatório" e com sua consequente degradação ao meio ambiente, foram criadas, nos EUA, as primeiras áreas protegidas, dentre as quais, o Parque Nacional de Yellowstone foi a primeira, em 1872. Apesar de garantir a proteção da fauna e da flora presentes em seus limites, as áreas protegidas estadunidenses criaram conflitos sociais, já que não permitiram a permanência de co- 
munidades já estabelecidas há muito tempo naqueles locais.

No Brasil, o Sistema Nacional de Unidades de Conservação (SNUC), regulamentado pela Lei no 9.985/2000, segue o estabelecido por esse modelo, criando Unidades de Conservação de Proteção Integral federais, em que seus moradores, populações tradicionais, não podem permanecer, mesmo quando lá residem antes da criação dessas áreas protegidas, tendo que se retirar para outra localidade, fazendo aumentar o estereótipo de separação entre homem e natureza. O SNUC define Unidades de Conservação como áreas "com características naturais relevantes". Então, a visão do Estado e de algumas associações ambientalistas é, muitas das vezes, excludente quanto à dimensão social, histórica e cultural nesses casos em questão. Os órgãos ambientais estaduais seguem esse modelo, ao criar Unidades de Conservação de sua responsabilidade.

As comunidades tradicionais que, antes de tudo, são comunidades biológicas e têm raízes fortes com sua terra, algumas vezes, são tratadas como destruidoras dos espaços "de relevância natural" por parte dos representantes dos órgãos ambientais. Porém, como dependem intrinsecamente da natureza, têm grande conhecimento sobre os recursos encontrados no meio natural, o que demonstra uma percepção profunda e peculiar sobre os recursos naturais. E, ainda mais, o homem adapta-se ao "seu" ambiente, assim como "seu" ambiente também sofre adaptações conforme o uso que essa população Ihe dá, como afirma Adams (2000, p.165):

\begin{abstract}
Se essas populações realmente viessem a desaparecer, ou a serem definitivamente removidas de suas áreas originais de ocupação, poderíamos esperar alterações na dinâmica de recomposição das florestas e na composição específica. Mas, certamente, a maior perda seria na diversidade cultural e na relação entre biodiversidade e sociodiversidade, e não somente na biodiversidade, como se afirma.
\end{abstract}

Dessa forma, a conservação da natureza ocorre, porém esquece-se da relação dessas populações com o meio, sendo esse uma fonte de recursos para sua subsistência, bem como suporte para sua vida e bem-estar.

Diegues (2001) cita que o afastamento não-consensual das populações das áreas protegidas, ou melhor, de sua terra, para beneficiar os "visitantes urbanos" é de se questionar porque, "na maioria das vezes, é usurpação de espaços coletivos, habitados por populações com grande tradição de saber e fazeres patrimoniais". Acontece um processo de desenraizamento de sua terra, de desprendimento de seus costumes, e, no afã de continuar em seu lugar, acabam por adaptar-se a novas tecnologias, no sentido de trazer elementos a que os "de fora" estão acostumados.

A relação dos moradores do Aventureiro com o INEA é conflituosa, por ser este o representante estatal das duas Unidades de Conservação: Parque Estadual Marinho do Aventureiro e Reserva Estadual Biológica da Praia do Sul, que influenciam diretamente no cotidiano da comunidade. Exemplo disso são as palavras de uma moradora, em uma das reuniões que a comunidade teve com o INEA: "Antes, a gente ficava aqui isolado e ninguém nem queria saber da gente. Agora, ficam sempre aqui que- 
rendo tomar conta do que a gente faż'. Sua vida está submetida à tutela do Estado, a visão da população e a visão institucional do Instituto Estadual do Ambiente (INEA) se contrapõem em algumas ocasiões. Enquanto, para a comunidade, a palavra dita é o que vale, dentro de relações de confiança, para o INEA, importa o que está escrito, e nessa diferença pode estar o cerne do conflito entre eles.

O que se pode dizer, de acordo com a experiência citada acima é que as Unidades de Conservação e órgãos ambientais, dessa forma, acabam por fazer o caminho reverso à sustentabilidade a que se propõe, quando separam o homem da natureza, sugerindo a retirada das populações estabelecidas historicamente no local que transformam em áreas protegidas. Tornam-se insustentáveis quando não é feita a reflexão sobre aspectos socioculturais, como a dependência, pelas populações, da natureza, que é sua fonte de recursos e suporte de sua vida, a produção e a vida baseadas principalmente em elementos naturais e as consequências da retirada dessas populações, como sua segregação em favelas de grandes cidades, sem perspectivas e tendo perdido também sua história, sua memória, sua identidade.

\section{Gestão participativa e geração de capital social}

O homem naturalmente precisa viver em sociedade. A comunidade é uma unidade na diversidade, visto que há membros e representantes cujas perspectivas individuais diferem entre si, mesmo que haja uma construção identitária, comum a eles. Todavia, segundo Paiva (2007, p.09), a comunidade não pode ser vista como um "mero estar-junto num território", mas como "um compartilhamento (ou uma troca)", em que cada um tem uma vinculação de responsabilidades para com o outro, apesar de suas diferenças, existindo uma ordem social.

Como propõem Baquero e Cremonese (2006, p.132), "a ordem social somente torna-se possível se houver estabilidade das relações", que diminua as incertezas e aumente a confiança entre os membros da sociedade. Assim, pressupomos que haja uma estabilidade maior e um estreitamento nas relações, sendo que não há uma confiança cega, mas baseada em acontecimentos que comprovem que as relações sociais são estáveis.

A confiança é tida como um dos componentes cruciais do Capital Social, que Baquero e Cremonese (2006, p.204) mostram como variável principal, junto com "a cooperação e a participação". Os autores indicam que as "redes de confiança" (op. cit., p.209) são pressuposto essencial na geração do Capital Social já que as sociedades são mais eficazes e eficientes a partir do momento em que "os cidadãos confiam uns nos outros e trabalham cooperativamente em prol do bem comum" (op. cit., p. 259).

O Capital Social, para Putnam (2002, p.177), está ligado a "características da organização social, como confiança, normas e sistemas, que contribuam para aumentar a eficiência da sociedade", através da cooperação entre seus membros, que, 
supõe-se, é espontânea. Além disso, Baquero e Cremonese (2006) colocam que ele está intrinsecamente envolvido com a cultura que, "ao ligar as pessoas para que atuem não só no conjunto, mas, antes, em conjunto, cria formas específicas de relacionamento com comportamentos selecionados visando sua perpetuação". Essas formas de relacionamento, por mais que parecidas em algumas comunidades, apresentam peculiaridades inerentes apenas àquele grupo, que o diferenciam dos demais.

Por meio das redes de relações, a comunidade tende a "produzir e reproduzir relações duráveis e úteis para proporcionar lucros materiais e simbólicos" (op. cit., p. 231) e a ganhar força contra uma (in)sustentabilidade imposta, de cima para baixo, de fora para dentro, que, porventura, invisibilize as características próprias da comunidade.

A mobilização social é uma forma de se mostrar a importância da participação democrática da comunidade local, destacando que quanto menor for a interferência e a dependência da ação estatal, mais efetiva se torna a comunidade em sua atuação participativa. Essa mobilização forma uma consciência sobre ganhos e responsabilidades partilhados, causando o empoderamento da comunidade, buscando "dotar os indivíduos de autonomia e de capacidade de intervenção de modo a Ihes permitir uma vida autodeterminada e autorresponsável' (BAQUERO; CREMONESE, 2006, p.261) não só na participação pura e simples, mas na tomada de decisão.

No Aventureiro, como em outras comunidades chamadas "caiçaras", as atividades são exercidas com mutirão, em que familiares, compadres e comadres se ajudam, recebendo o referente a uma parcela de seu trabalho. Exemplo disso é a pesca artesanal, quando mulheres e crianças que ajudam a puxar a rede e a desmalhar o peixe, além dos homens que foram pescar, recebem uma parte dos peixes como pagamento. Essas relações reforçam a solidariedade dentro do grupo, apesar do quê, os mutirões são, atualmente, exercidos com menos frequência, mas ainda existem, como pudemos observar em campo.

Em contrapartida, o que acontece no Aventureiro é que as relações de confiança tornaram-se processos desacreditados, porque a população passou por diversos marcos históricos de cerceamento, interdição cultural, perda total e parcial do território, provenientes de conflito gerado pela criação imposta da RBEPS, seguidas de sucessivas fiscalizações e aplicações de multas, que se repetem desde então. Não há ordem, não há estabilidade, mas um desgaste da relação população-INEA.

O empoderamento está em refletir e agir no cotidiano, para que efetivamente, os indivíduos intervenham em sua própria realidade, "no despertar do senso de responsabilidade, de solidariedade e de cooperação" (op. cit., p. 262). Dessa forma, vaise em direção à sustentabilidade para o lugar, para as pessoas, para a comunidade em si, sem que seja imposta por organizações e entidades "de fora", mas como uma necessidade do indivíduo e, por conseguinte, do grupo, reforçando o sentimento de pertencimento, tornando-os autores de sua própria história, base para a gestão efetivamente participativa. 
Silva, J.F.; Brandão, J.O.S.

\section{Raízes: tradição, memória e identidade}

Como as comunidades tradicionais têm raízes com seu território, por mais que estejam abertas para elementos culturais das sociedades modernas, como o Turismo, suas tradições são conservadas na essência, ainda que haja adaptações. Nesse sentido, Le Goff (1990) descreve a memória como "propriedade de conservar certas informações", sendo uma forma de reviver acontecimentos e conhecimentos do passado. Contudo, segundo Diehl (2002), não se pode mais recorrer à memória apenas para fazer essa busca no passado, mas como um "processo dinâmico da própria rememorização", em que o passado é revisitado ao mesmo tempo em que o presente é vivido como continuação do passado, por fim, aglutinando-se passado e presente na construção da identidade.

Pollak (1992) caracteriza a memória como sendo um fenômeno construído coletivamente e submetido a flutuações, transformações e mudanças constantes. Certamente, a memória também é individual, mas seu respaldo ocorre na coletividade, quando, com transformações e mudanças sociais, molda seus elementos herdados, estruturando sua identidade.

Pollak (1992) e Hall (2005) afirmam que a memória e a identidade estão relacionadas diretamente ao sentimento de pertencimento, de vínculo, "há uma ligação fenomenológica muito estreita entre a memória e o sentimento de identidade" (POLLAK, 1992, p.204), já que o que se observa é que todo o conhecimento transmitido e herdado, molda-se à identidade comunitária. Assim, cada indivíduo sente-se parte da coletividade, identificando-se com a vida social, garantindo a continuidade e a coerência do indivíduo para com o grupo; e do grupo para consigo mesmo e para com outros grupos sociais. Hall (2005) ainda cita que a identidade plenamente unificada, completa, segura e coerente é uma fantasia, o que significa dizer que ela não existe como amálgama, mas metamorfoseando-se.

Como a cultura é dinâmica, modifica-se no decorrer do tempo no espaço, de acordo com o sentido que o homem lhe dá, definindo e redefinindo significados conferidos a objetos e ao espaço. Como escreveu Geertz (1973, p.15), "o homem é um animal amarrado a teias de significados que ele mesmo teceu", e, nesse contexto, ele e a comunidade a que pertence tecem-na, produzindo sua história, sua vida, o seu sentido de ser. Como o conceito de cultura "é essencialmente semiótico" (GEERTZ, 1973, p.15), os comportamentos do homem, por assim dizer, podem ser abordados como essencialmente simbólicos, carregados de significado, que deve ser conhecido e aceito coletivamente para que se torne parte do modo de vida da comunidade.

As ações sociais que conferem sentido aos objetos e ao território formam o espaço específico e não-estático da comunidade, que cumpre as funções como recurso natural e como suporte da atividade humana. $E$ dentro da perspectiva, só se pode conceber o ambiente como espaço social de acordo com o uso que os grupos humanos lhe dão, através de seu trabalho e suas relações sociais. 


\section{Turismo comunitário: reavivador da memória}

O Turismo Comunitário, também chamado "Turismo de Base Local", surge com uma singularidade que o diferencia das demais formas de gestão, que é o poder endógeno para a condução das atividades, prezando pela sustentabilidade do lugar, já que, no atual contexto, seu desenvolvimento está submetido ao reducionismo econômico.

Segundo conceito de Seabra (2007, p.103), ainda em relação à sustentabilidade do Turismo de Base Local, é "uma forma de lazer harmoniosa, fundamentada na autodeterminação, na valorização das populações nativas e no respeito ao meio ambiente". São aspectos como os aqui apresentados que podem trazer benefícios aos moradores e aos turistas, ao participarem de uma vivência real da cultura do lugar.

O Turismo Comunitário surge como alternativa, também, para aumentar o ganho monetário da comunidade, tendo como objetivo principal "assegurar o bem-estar comum e garantir a sobrevivência de seus membros, preservando sua própria identidade cultural' (BARTHOLO, 2009, p.28), porque a própria comunidade tende a reconhecer o valor de seu modo de vida, de sua identidade.

Através de organizações sociais, ela é responsável por ações para gerar seu desenvolvimento socioeconômico e pela preservação de seu patrimônio comunitário, tanto ambiental como cultural. E é esse diferencial que atrai visitantes dos mais distintos destinos, principalmente os mais interessados em conhecer lugares que tenham as suas características identitárias mantidas em sua essência, "a partir da própria comunidade, na qual promove sua convivencialidade" (GRIMM; SAMPAIO, 2011, p.58).

Podemos perceber que, quando há inclusão da comunidade no processo de organização, planejamento e gestão das atividades locais, ela toma para si, também, a responsabilidade pela gestão do Turismo. Acreditamos que o comprometimento dos agentes locais é fator fundamental para a ocorrência harmônica do Turismo.

São os aspectos ligados ao modo de vida da população que auxiliam na atratividade do destino, visto que trazem consigo toda a bagagem cultural, refletindo diretamente na relação turista-morador. Dessa forma, se o planejamento da atividade turística parte dos residentes, por meio de organização social, há maiores possibilidades de que práticas desenvolvidas sejam direcionadas ao bem-estar comum da população.

O Turismo Comunitário oferece ao visitante a oportunidade de participar como um agente propriamente dito nas relações tecidas por meio das experiências comunitárias, e é isso que, muitas vezes, faz do turista um mero expectador, visto que se envolve no processo cultural da comunidade visitada.

Segundo Magalhães (2002), existem necessidades para que o fenômeno turístico aconteça com vistas a proporcionar ao turista novas emoções e superação de expectativas, tais como participar do modo de vida e dos eventos nas comunidades, 
ou simplesmente ter um contato maior com a natureza em ambientes mais tranquilos e menos populosos, diferentes do local de origem do turista caracterizado urbano.

Diante de todo o exposto, percebe-se que o Turismo Comunitário traz consigo o reavivamento da memória da comunidade, já que "fomenta a relação social entre modos de vida distintos, resgatando e reconstruindo o interesse pelo outro, [...] pela alteridade" (GRIMM; SAMPAIO, 2011, p.58). Com o interesse do turista pelo diferente, pelo "exótico" - aos seus olhos -, a comunidade pode perceber o valor que têm suas tradições, tomando para si a responsabilidade de aprender e ensinar aos turistas como vivem, fazendo-os novos protagonistas dessa história; e aos jovens moradores, para que se sintam pertencentes ao grupo e levem adiante as tradições que os diferem dos demais, e que são atrativas ao turista interessando nas diferenças.

Há, no Aventureiro, um projeto de Turismo Comunitário, criado por estudiosos da Universidade Federal Rural do Rio de Janeiro (UFRRJ), por meio do qual, os moradores puderam aprender, em oficinas, sobre temas ligados à hospitalidade, gastronomia, ao Turismo de forma geral. Porém, quando perguntados sobre a eficácia do projeto, alguns moradores nos disseram que foi bom no início, mas as pessoas não iam com tanta frequência participar das oficinas depois de um tempo. Além disso, pelo relatado, o que aprenderam não estava totalmente de acordo com seus conhecimentos tradicionais, mas eram saberes trazidos "de fora" da comunidade. Dessa forma, tomo como exemplo a gastronomia local, baseada nos produtos da terra e do mar, e que não foram valorizados. Cabe dizer que a gestão do Turismo de Base Local ressalta a ética e a cooperação nas relações sociais e, como citam Grimm e Sampaio (2011), valoriza os recursos específicos de um território.

\section{Conclusão}

Para perceber o Turismo como um fenômeno entre um complexo de relações envolvidas entre as partes e o todo, o meio em que a atividade acontece, temos, primeiramente, que romper com a visão economicista que recai sobre a forma que se planeja e executa o Turismo.

O desenvolvimento da comunidade com atividades partilhadas para o bem comum, e cujos saberes de vida são transmitidos através das gerações, é sustentável, como ocorre com a Vila do Aventureiro que, por suas práticas tradicionais, é naturalmente sustentável. Contudo, podem ser percebidos alguns costumes interditados no campo do "fazer", condição que foi imposta pelo órgão ambiental.

A cooperação entre os membros da comunidade cria formas de relacionamento direcionado à sua continuidade e, por meio de mobilização, a comunidade pode se unir para gerir sua vida e escrever sua história com as próprias mãos, o que caracteriza o processo de empoderamento. No Aventureiro, apesar da solidariedade tradicional, notamos um certo desgaste nas relações de confiança, ocasionado pelos marcos históricos de interdição cultural.

O Turismo Comunitário abarca a possibilidade de a população decidir como 
deseja que a atividade seja realizada e, principalmente, como os recursos serão utilizados, rompendo com a lógica de um modelo de produção excludente.

Quando a comunidade é incluída nos processos de gestão, o Turismo ocorre de forma mais autêntica, já que seu modo de vida, "exótico" na perspectiva do turista, é o que o atrai às comunidades tradicionais. O Turismo Comunitário, assim, reaviva a memória, no sentido de que a comunidade ensina ao turista interessado no diferente, ao mesmo tempo em que traz para seu meio o jovem morador, fazendo-o notar o valor de suas tradições e sentir-se pertencente ao grupo. Qualquer projeto de Turismo Comunitário precisa estar intrinsecamente ligado ao modo de vida da comunidade e sua vivência real por parte do turista, valorizando as peculiaridades.

\section{Referências bibliográficas}

ADAMS, C. As Populações Caiçaras e o Mito do Bom Selvagem: a necessidade de uma nova abordagem interdisciplinar. In: Revista de Antropologia, São Paulo, USP, n. 1, vol. 43, 2000.

BAQUERO, M.; CREMONESE, D. (orgs.). Capital Social: teoria e prática. ljuí: Editora Unijuí, 2006.

BARTHOLO, R.; SANSOLO, D.G.; BURSZTYN, I. (orgs.). Turismo de base comunitária: diversidade de olhares e experiências brasileiras. Rio de Janeiro: Ed. Letra e Imagem, 2009.

BIDEGAIN PRIMO, P.; FRESCHI, J.M. Situação Geral do Povoado do Aventureiro, da Reserva Biológica da Praia do Sul e do Parque Estadual Marinho do Aventureiro, Relatório Final, Volume I. Rio de Janeiro, Secretaria de Estado do Ambiente, Grupo de Trabalho do Aventureiro, 2009.

BRASIL. Sistema Nacional de Unidades de Conservação. Lei 9.985/2007.

BUARQUE, S.C. Construindo o Desenvolvimento Sustentável. Recife, 2001.

CAPRA, F. A Teia da Vida: uma nova compreensão científica dos sistemas vivos. São Paulo: Editora Cultrix, 1996.

CMMAD - COMISSÃO MUNDIAL SOBRE MEIO AMBIENTE E DESENVOLVIMENTO. Nosso Futuro Comum. $2^{\underline{a}}$ Ed. Rio de Janeiro: Editora da Fundação Getúlio Vargas, 1991.

DECKER, A.F.M. Pesquisa em Turismo: planejamento, métodos e técnicas. São Paulo: Futura, 1998.

DIAS, G.F. Ecopercepção: um resultado didático dos desafios socioambientais. São Paulo: Gaia, 2004.

DIEHL, A.A. Cultura Historiográfica: memória, identidade e representação. São Paulo: EDUSC, 2002. 
DIEGUES, A.C. O Mito da Natureza Intocada. São Paulo: HUCITEC, 2001.

GEERTZ, C. A Interpretação das Culturas. Rio de Janeiro: Zahar, 1973.

GRIMM, I.J.; CIOCE, C.A. Turismo de Base Comunitária: convivencialidade e conservação ambiental. In: Revista Brasileira de Ciências Ambientais, n. 19. Março, 2011.

HALL, S. A Identidade Cultural na Pós-Modernidade. 10 $\mathrm{a}$ Ed. Rio de Janeiro: DP\&A Editora, 2005.

HARDIN, G. The Tragedy of the Commons. E Science, n. 3859, vol. 162 December, 1968.

LARAIA, R.B. Cultura: um conceito antropológico. 14aㅗ ed. Rio de Janeiro: Jorge Zahar Editor, 2001.

LE GOFF, J. História e Memória. Campinas: Editora da UNICAMP, 1990.

MAGALHÃES, C.F. Diretrizes para o Turismo Sustentável em Municípios. São Paulo: Ed. Roca, 2002.

MORIN, E. Introdução ao Pensamento Complexo. Tradução Eliane Lisboa. 4a Ed. Porto Alegre: Sulina, 2011.

PAIVA, R. (org.). O Retorno da Comunidade: os novos caminhos do social. Rio de Janeiro: Mauad X, 2007.

PENA, L.C.S.; BRASILEIRO, I.L.G.; SANTOS, A.R.D. Processos Participativos e do Desenvolvimento Sustentável do Turismo: reflexões sobre o funcionamento do Grupo Gestor do Destino Indutor Brasília. Revista Turismo \& Desenvolvimento, n. 17/18, volume 2, 2012.

POLLAK, M. Memória e Identidade Social. Estudos Históricos, Rio de Janeiro, vol. 5, n. 10, p. 200-212, 1992.

PUTNAM, R. D. Comunidade e Democracia: a experiência da Itália moderna. Rio de Janeiro; Editora Fundação Getúlio Vargas, 1996.

SAHLINS, M.. Cultura e Razão Prática. Rio de Janeiro; Zahar, 2003.

SANTOS, M.S. Os Porões da República: a colônia correcional de Dois Rios entre 1908 e 1930. TOPOI, v. 7, n. 13, jul.-dez. 2006.

SEABRA, G. (org.). Turismo de base local: identidade cultural e desenvolvimento regional. João Pessoa: Ed. Universitária/ UFPB, 2007.

VILAÇA, A.M.N.; MAIA, A.A. O povo do Aventureiro. In: PRADO, R.M. (org.). Iltha Grande: do Sambaqui ao Turismo. Rio de Janeiro: Garamond: EDUERJ, 2006. 
Juliana Fernandes da Silva: Universidade de Brasília, Brasília, DF, Brasil.

Email: julianafernan10@yahoo.com.br

Link para o currículo Lattes: http://lattes.cnpq.br/8570775788671949

Juzânia Oliveira da Silva Brandão: Universidade de Brasília, Brasília, DF, Brasil.

Email: juzania@gmail.com

Link para o currículo Lattes: http://lattes.cnpq.br/3565000708470108

Data de submissão: 30 de junho de 2012

Data de recebimento de correções: 06 de maio de 2013

Data do aceite: 06 de maio de 2013

Avaliado anonimamente 